\title{
An Unusual Presentation Of An Inverted Dilacerated Mesiodens
}

\section{Sharma U}

\begin{abstract}
The paper presents an inverted dilacerated mesiodens which had crossed over the permanent incisor to form a characteristic hook-like tooth thus exhibiting an uncommon occurrence.
\end{abstract}

Keywords: Dilaceration, mesiodens, impaction, surgical extraction

${ }^{1}$ Senior Lecturer

Department of Pedodontics and Preventive Dentistry Dr. HSJ Institute of Dental Sciences and Hospital Panjab University, Chandigarh, INDIA

\section{Contact Author}

Dr. Urvashi Sharma urvashi233@gmail.com

J Oral Health Comm Dent 2014;8(3)125-127

\section{INTRODUCTION}

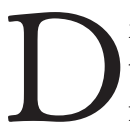
ilaceration refers to an angulation in the root/ crown of the formed tooth (1). It occurs commonly due to intrusive trauma sustained to the deciduous predecessor during odontogenesis. It may also be caused by an adjacent cyst, tumour or hamartoma or may be of unknown etiology (2). The extent of malformation depends upon the age of the patient, degree and the direction of the driving force. It frequently involves the maxillary incisors followed by the mandibular anteriors and occasionally, the deciduous teeth. Dilaceration creates difficulties during extraction, root canal therapy, prosthetic and orthodontic treatment. A dilacerated tooth may also fail to erupt or sometimes, may erupt ectopically.

Supernumerary teeth are extra teeth that are in addition to those of the normal series. They occur more in the maxilla $(8: 1)$; more in the males $(2: 1)$ and more in the permanent dentition $(1.5-3.5 \%)$ than in the primary dentition $(0.3-0.8 \%)$ (3). Their prevalence in the Caucasian population is $1-3 \%$ (4). 'Mesiodens' is the most common supernumerary tooth which is situated between the maxillary central incisors. It is usually a small tooth with a conical crown and a conical root.
Various etiological theories postulated for supernumerary teeth are an excessive but organized growth of dental lamina to form a third tooth germ, splitting of the permanent tooth bud, hereditary factors and atavism (5). They may also be associated with syndromes like Cleidocranial dysplasia, Gardner's syndrome, HallermannStreiff's syndrome, oro-facial digital syndromes, cleft lip and palate, etc.

Supernumerary teeth often cause delayed eruption or malposition of adjacent teeth, midline diastema, odontogenic cysts, caries, gingival and periodontal problems apart from being unaesthetic. They can also cause displacement, resorption and impaction of adjacent teeth.

I report here a patient with an unusual presentation of an inverted dilacerated mesiodens that had crossed over the crown of a permanent maxillary right central incisor, thus, impeding its eruption.

\section{CASE REPORT}

A ten-year old female patient reported with a chief complaint of non-eruption of the upper right front tooth. Medical and family history was non-contributory.

The clinical examination revealed all 
erupted permanent incisors except for the right upper central incisor in place of which a pronounced bulge was evident on the labial aspect (Fig. 1). The hard bulge conformed to the shape of the crown of the permanent maxillary central incisor. The overlying gingiva was normal in colour and texture. A fully erupted mesiodens was visible mesial to the upper left central incisor.

An intra-oral periapical radiograph depicted an unusual pathology. The unerupted permanent maxillary right central incisor was in its proper position but its eruption path was impeded by yet another inverted and palatally placed mesiodens. The root of the unerupted mesiodens was however, dilacerated which had caused it to cross over from palatal to the labial aspect, overlying the crown of the unerupted upper right central incisor, giving it a characteristic hook-like appearance (Fig.2).

The erupted mesiodens was extracted under local anesthesia whereas the inverted dilacerated mesiodens was surgically extracted (Fig 3).

\section{DISCUSSION}

The presence of supernumerary teeth is one of the commonest factors responsible for delayed eruption or impaction of the permanent incisors (6). In our case, all the permanent incisors had erupted save the permanent maxillary right central incisor. Srivastava et al

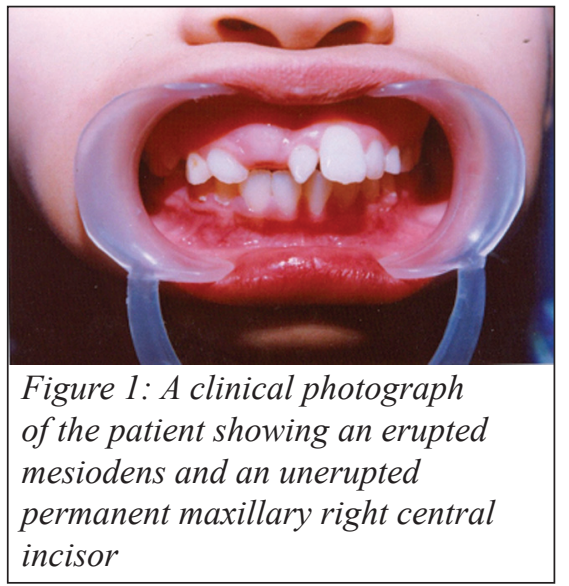

stated that the occurrence of impaction of maxillary central incisors in association with mesiodens was more frequently observed in Asians (7).

Severe trauma to the primary tooth during odontogenesis may lead to necrosis and sequestration of the permanent tooth bud. Trauma in the initial developmental stages of a tooth can result in the formation of a complex odontoma whereas a force of a comparatively lower intensity may result in a geminated and/or a hypoplastic tooth. The anomalies of the tooth roots occur as a result of damage to the Hertwig's root sheath or during the developmental period. It is caused usually by trauma to the developing tooth and can form an angulated root. Such a trauma could be a possibility in this case as well leading to a dilacerated mesiodens although the patient and her parents could not recollect any such incident.

Laskin stated that a mesiodens is best removed after complete root formation of permanent teeth to avoid injury to the developing permanent teeth unless it interferes with their normal eruption

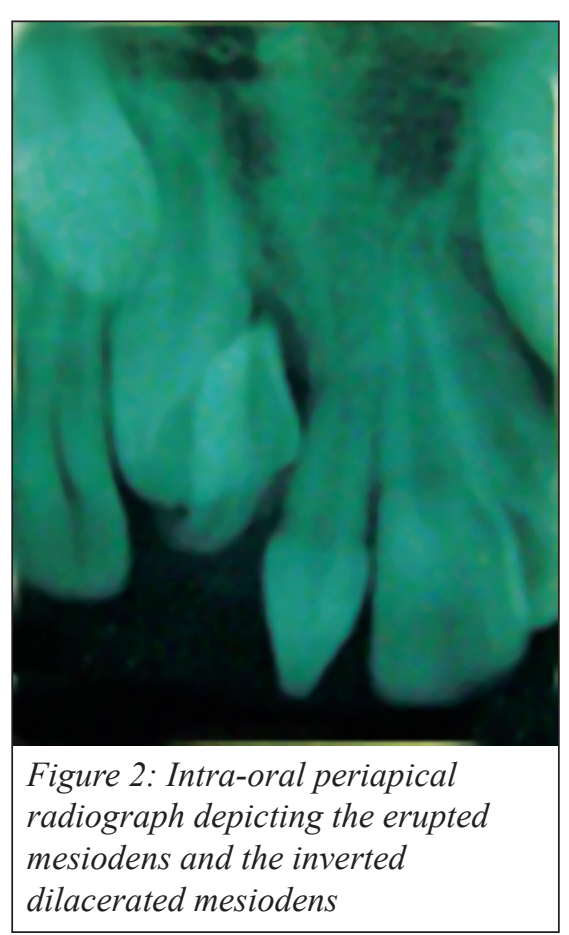

(8). In our patient, extraction of the mesiodens was carried out as it had caused a mechanical obstruction to the impacted incisor, thereby preventing its eruption.

During treatment planning, maturity of the unerupted incisors is a vital factor governing tooth eruption. Mason et $\mathrm{al}$ in a retrospective review of a hundred patients showed that almost three-quarters of immature permanent maxillary central incisors had erupted spontaneously after removal of the associated supernumerary teeth (3). Brand et al concluded from their study that younger the patient, faster would be the tooth eruption (9). The fact that the closed apices are associated with slow movement and that the maturity affects the eruption of the tooth is further corroborated in the study conducted by Michel et al who stated that given sufficient space and time, majority of the unerupted teeth, prevented from eruption by supernumerary teeth, will erupt spontaneously following removal of the obstruction (10). In our case, the incisor erupted within six months of the surgical removal of the unerupted dilacerated mesiodens. This could be attributed to the immaturity of the root apex and also to the lack of overlying bone on the unerupted permanent central incisor.

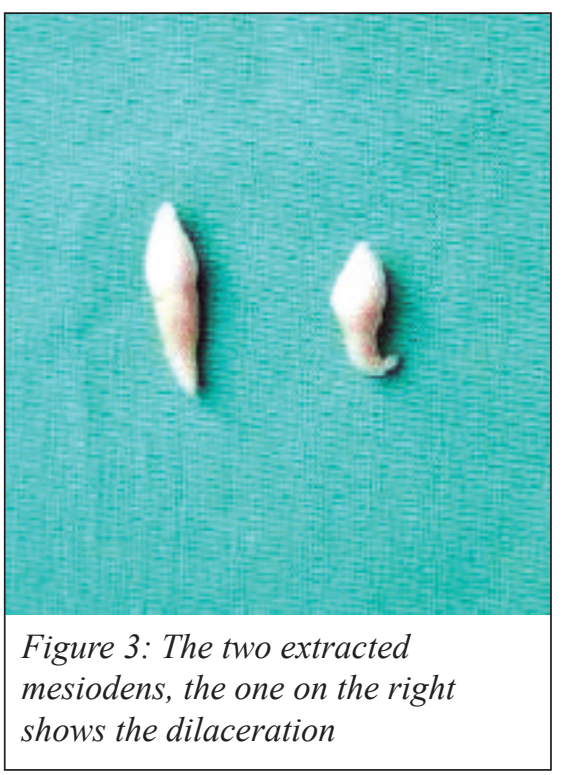


In conclusion, this study stresses upon the importance of early diagnosis and treatment. For a satisfactory outcome, extraction of mesiodens should be carried out at the very outset if it interferes with the eruption of the permanent teeth.

\section{REFERENCES}

1. Shafer GS. Developmental disturbances of oral and paraoral structures. In Shafer GS, Hine MK, Levy BM, editors. A textbook of Oral Pathology. 4th ed. Philadelphia: WB Saunders; 2003:p4750 .

2. Neville BW. Abnormalities of the teeth. In Neville BW, Douglas DD, Allen CM, editors. Oral and maxillofacial pathology. 2nd ed. Philadelphia: WB Saunders; 2004:p.70-88.

3. Mason C, Azam N, Holt RD, Rule§ DC. A retrospective study of unerupted maxillary incisors associated with supernumerary teeth. Brit J Oral and Maxillofacial Surg 2000;38:62-65.

4. Gallas MM, Garcia A. Retention of permanent incisors by mesiodens: A family affair. Br Dent J 2000;188:63-64.

5. Ibricevic $\mathrm{H}, \mathrm{Al}-\mathrm{Mesad} \mathrm{S}$, Mustagrudic D, Al-Zohejry N. Supernumerary teeth causing impaction of permanent maxillary incisors: consideration of treatment. J Clin Pediatr Dent 2003;27(4):327-32.

6. DiBiase DD. Midline supernumeraries and eruption of maxillary central incisors. Dent Pract Dent Rec 1969;20:35-40.
7. Srivastava N, Srivastava V. An inverted supernumerary tooth. Report of a case. J Dent Child 2001;68:61-62.

8. Laskin DM. Excision of unerupted and impacted teeth- odontectomy. Laskin DM, ed. Oral and maxillofacial surgery. New Delhi: AITBS 2009:p96-97.

9. Brand A, Akhavan M. Tong H, Kook YA Zernik J. Orthodontic, genetic and periodontal consideration in the treatment of impacted maxillary incisors: A study of twins. Am J Orthod Dentofacial Orthop 2000;117:68-74.

10. Mitchell L, Bennet TG. Supernumerary teeth causing delayed eruption- a retrospective study. Br J Orthod 1992;19:

41-46. 